\title{
MicroRNA-146a modulates B-cell oncogenesis by regulating Egr1
}

\author{
Jorge R. Contreras ${ }^{1,2}$, Jayanth Kumar Palanichamy ${ }^{1}$, Tiffany M. Tran ${ }^{1}$, Thilini R. \\ Fernando ${ }^{1}$, Norma I. Rodriguez-Malave ${ }^{1,2}$, Neha Goswami ${ }^{1}$, Valerie A. Arboleda ${ }^{1}$, \\ David Casero ${ }^{1}$, Dinesh S. Rao ${ }^{1,3,4}$ \\ ${ }^{1}$ Department of Pathology and Laboratory Medicine, UCLA, Los Angeles, CA USA \\ ${ }^{2}$ Cellular and Molecular Pathology Ph.D. Program, UCLA, Los Angeles, CA USA \\ ${ }^{3}$ Jonsson Comprehensive Cancer Center, UCLA, Los Angeles, CA USA \\ ${ }^{4}$ Broad Stem Cell Research Center, UCLA, Los Angeles, CA USA \\ Correspondence to: \\ Dinesh S. Rao, e-mail: drao@mednet.ucla.edu \\ Keywords: microRNA, B-cell, lymphoma, leukemia, c-Myc \\ Received: January 26, $2015 \quad$ Accepted: February 24, $2015 \quad$ Published: April 13, 2015
}

\section{ABSTRACT}

miR-146a is a NF-KB induced microRNA that serves as a feedback regulator of this critical pathway. In mice, deficiency of miR-146a results in hematolymphoid cancer at advanced ages as a consequence of constitutive NF-KB activity. In this study, we queried whether the deficiency of miR-146a contributes to B-cell oncogenesis. Combining miR-146a deficiency with transgenic expression of $\mathrm{c}-$ Myc led to the development of highly aggressive B-cell malignancies. Mice transgenic for C-Myc and deficient for miR-146a were characterized by significantly shortened survival, increased lymph node involvement, differential involvement of the spleen and a mature B-cell phenotype. High-throughput sequencing of the tumors revealed significant dysregulation of approximately $\mathbf{2 5 0}$ genes. Amongst these, the transcription factor Egr1 was consistently upregulated in mice deficient for miR-146a. Interestingly, transcriptional targets of Egr1 were enriched in both the high-throughput dataset and in a larger set of miR-146a-deficient tumors. miR-146a overexpression led to downregulation of Egr1 and downstream targets with concomitant decrease in cell growth. Direct targeting of the human EGR1 by miR-146a was seen by luciferase assay. Together our findings illuminate a bona fide role for miR-146a in the modulation of B-cell oncogenesis and reveal the importance of understanding microRNA function in a cell- and disease-specific context.

\section{INTRODUCTION}

MicroRNAs (miRNAs) are a class of small noncoding RNAs, 21-22 nucleotides in length, which have physiological roles in many developmental systems [1]. miRNAs primarily act through post-transcriptional repression of target mRNAs via short complementary sequences in the 3 'untranslated region (UTR) of mRNA transcripts [2, 3]. It has been reported that nearly 2000 miRNAs exist in the human genome and more than half of protein-coding genes are potential targets for miRNAs [4]. Both oncogenic and tumor suppressive miRNAs have been described in oncogenesis, acting via repression of tumor-suppressive and growth-promoting targets, respectively [5-8]. It is important to note, however, that miRNA regulation of gene expression is highly contextdependent: they regulate a cell type-specific transcriptome generated by a set of oncogenic or developmental transcriptional regulators. Hence, uncovering the oncogenic role of a miRNA requires the study of lineage specific transcriptional dysregulation.

miR-146a was discovered as a transcriptional target of the NF- $\kappa$ B pathway acting as a negative feedback regulator of this pathway and repressing some key components, such as Traf6 and Irak1 [9-13]. In line with its function in the NF- $\kappa$ B pathway, miR-146a deficiency in mice results in the development of a hyper inflammatory phenotype characterized by myeloid proliferation, lymphoid 
hyperplasia, T-cell hyper activation and autoantibody production [9, 11, 14, 15]. Subsequently, aged knockout mice develop myeloid and lymphoid malignancies $[9,11]$. These phenotypes are characterized by a dependence on constitutive NF- $\mathrm{kB}$ activity, as demonstrated by the correction of many phenotypes by deletion of elements of $\mathrm{NF}-\kappa \mathrm{B}$ signaling or downstream mediators $[11,16]$.

Constitutive NF- $\mathrm{kB}$ activity is a hallmark of many different types of cancer including $\mathrm{B}$-cell malignancies [17]. The activated B-cell type of diffuse large B-cell lymphoma (ABC-DLBCL), which demonstrates constitutive NF- $\mathrm{KB}$ activation, is more aggressive and leads to worse outcomes in patients. Currently, several components of the NF- $\mathrm{KB}$ pathway have been found mutated in DLBCL, producing activation of NF- $\mathrm{\kappa B}$ $[18,19]$. The role of miR-146a as a negative regulator of this critical pathway, along with the development of B-cell malignancies in knockout mice, suggest that loss of miR-146a via undefined mechanisms may represent a pathogenetic event in B-cell malignancies that contributes to constitutive NF- $\kappa \mathrm{B}$ activity.

In addition to being regulated by NF- $\mathrm{kB}$, miR146a has been shown to be positively regulated by the potent oncogene, $c-M y c$, in a melanoma cell line [20]. In contrast, primary samples of B-cell lymphoma with high levels of $c-M y c$ expression show dramatic downregulation of miR-146a expression, and additional studies demonstrate negative regulation of miR-146a by c-Myc [21-23]. This led us to question the role that miR-146a plays in $c-M y c$-mediated oncogenesis in the B-cell lineage. Since $c-M y c$ is a powerful transcriptional regulator with a specific transcriptome, we hypothesized that miR-146a mediated effects on the $c-M y c$ gene expression program would reveal unique cancer relevant pathways. To test our hypotheses, we intercrossed the E $\mu-M y c$ mouse with miR-146a-deficient animals. We found that miR-146a deficiency accelerates oncogenesis, decreases survival, and alters the differentiation stage of the tumors that are formed in the resulting mice. Histopathologic and flow cytometric analyses revealed a distinctive pattern of involvement in miR-146a-deficient animals. Mechanistically, few genes were significantly differentially regulated between wild-type and miR-146adeficient, $c-M y c$ driven tumors. Of these, Egrl and its downstream mediators were identified as a novel pathway regulated by miR-146a in B-cells. Our findings promise to open up a new area of research and demonstrate a tumor suppressive function for miR-146a in B-cell oncogenesis.

\section{RESULTS}

\section{miR-146a deficiency decreases survival of E $\mu$-Myc transgenic mice}

Given the proposed roles for miR-146a in tumor suppression and negative feedback regulation of the NF- $\mathrm{kB}$ pathway, we examined whether miR-146a deficiency would synergize with $c-M y c$ during B-cell oncogenesis. miR-146adeficient and $\mathrm{E} \mu-\mathrm{Myc}$ transgenic mice were bred to yield cohorts of mice that carried the E $\mu-\mathrm{Myc}$ transgene with wild-type, heterozygous or homozygous knockout alleles of miR-146a (Figure 1a-1b). Most tumors that formed in E $\mu$-Myc mice showed a lymphoblastic morphology with numerous mitotic figures and apoptotic bodies on H\&E sections (Figure 1c-1e). Conversely, tumors from the miR146a-deficient mice demonstrated a more heterogeneous appearance. Many tumors had lymphoblastic morphology, but others showed a plasmacytoid appearance, including eosinophilic cytoplasmic concretions, suggestive of immunoglobulin deposits (Figure 1e inset shows cells with immunoglobulin concretions). E $\mu-\mathrm{Myc}$ miR-146a ${ }^{+/-}$ mice did not have a significant reduction in their survival (Figure 1f). On the other hand, homozygous deficiency caused a decrease in survival from 104.5 days to 82.5 days (Figure 1f). Gender differences were noted, with female miR-146a $\mathrm{a}^{-1-}$ mice showing significant differences in survival, while males only showed a trend towards reduced survival (Supplementary Figure 1a-1d). Finally, virtually all mortality in both sets of mice was attributable to tumor formation (data not shown).

\section{miR-146a-deficient tumors demonstrate differential anatomic patterns of involvement}

Anatomically, tumors in both sets of mice showed differential patterns of involvement of hematopoietic and lymphoid organs, with virtually all mice showing thymic involvement. $31 \%$ of $\mathrm{E} \mu-\mathrm{Myc}$ miR-146a $\mathrm{a}^{+/+}$did not show any lymph node involvement, whereas all of the miR$146 \mathrm{a}^{-/-}$did show involvement (Figure 2a). While the majority of mice in both groups showed small numbers of circulating tumor cells in the peripheral blood, 6/10 E $\mu$ Myc miR-146a ${ }^{--}$mice examined showed frank leukemia (defined as a white blood cell count of greater than 30,000/ $\mu \mathrm{L})$ (Figure 2b-2d). This was in contrast to the lower numbers of $\mathrm{E} \mu-\mathrm{Myc}$ miR-146a $\mathrm{a}^{+/+}$mice that demonstrated leukemia by blood counts (4/14). Amongst mice with predominantly solid tumors, miR-146a deficiency caused a statistically significant increase in peripheral blood $\mathrm{CD} 11 \mathrm{~b}+$ myeloid cells but not in B220+ B-cells, CD3 $\varepsilon^{+}$ T-cells, hemoglobin or platelets (Supplementary Figure 2a-2f). This may represent the propensity of miR-146adeficient hematopoietic progenitors to produce increased numbers of myeloid cells. Bone marrow analysis of these mice found similar proportions of myeloid cells, erythroid cells, and B- lymphocytes (Supplementary Figure 2g-2i).

Mice in both groups demonstrated enlarged spleens, with average weights of approximately $400 \mathrm{mg}$ (SupplementaryFigure 3a). In E $\mu-M y c$ miR-146a ${ }^{+/+}$mice there was involvement of the white pulp with contiguous spread between the lymphoid follicles (Figure 2e, dotted area). High power views showed the malignant cells in both the white and red pulp (Supplementary Figure 3b$3 c)$. On the other hand, E $\mu-\mathrm{Myc}$ miR-146a $\mathrm{a}^{-/}$mice showed 


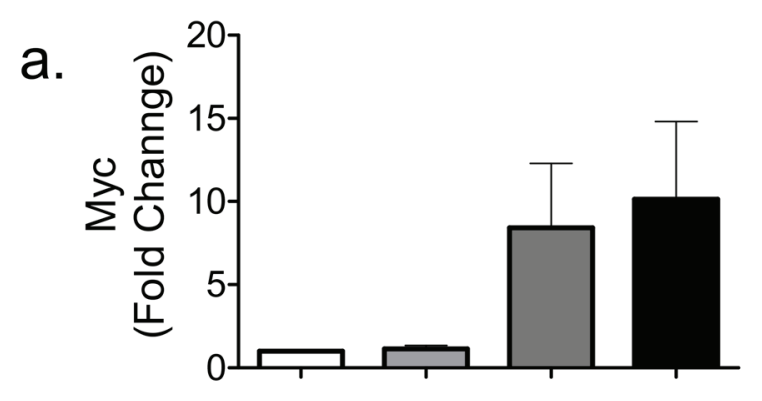

$\begin{array}{rrrrr}\text { miR-146a: } & +/+ & -/- & +/+ & -/- \\ \text { E } \mu-M y c: & \text { nc } & \text { nc } & \text { tg } & \text { tg }\end{array}$

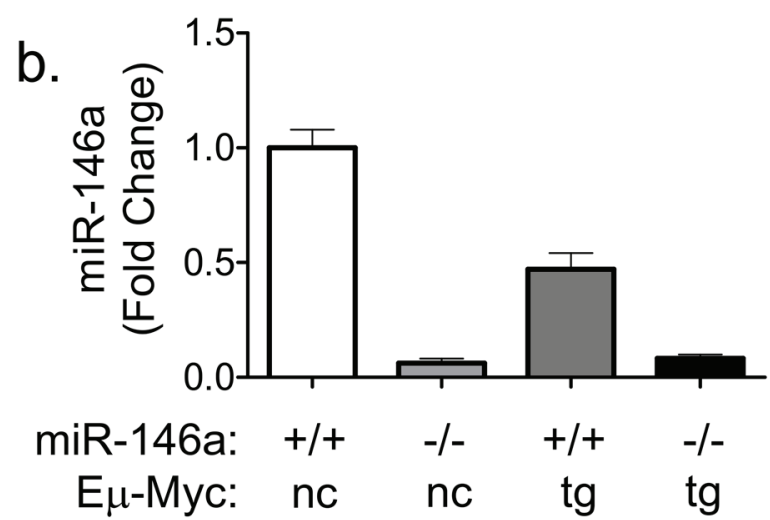

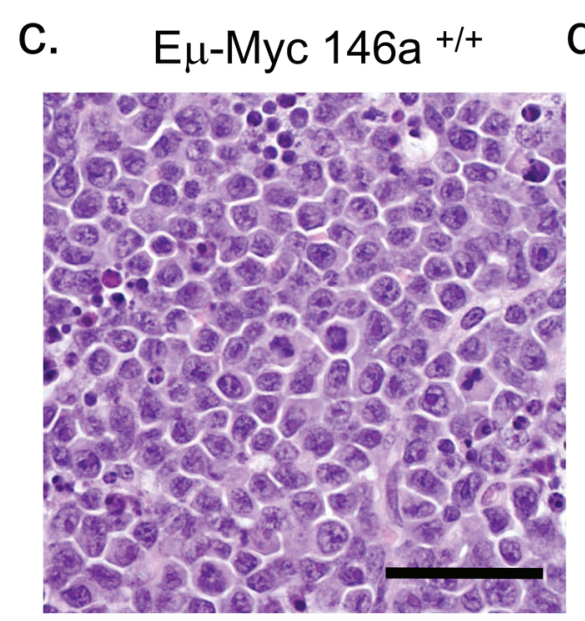

d. $\quad$ E $\mu-M y c 146 a^{+/-}$

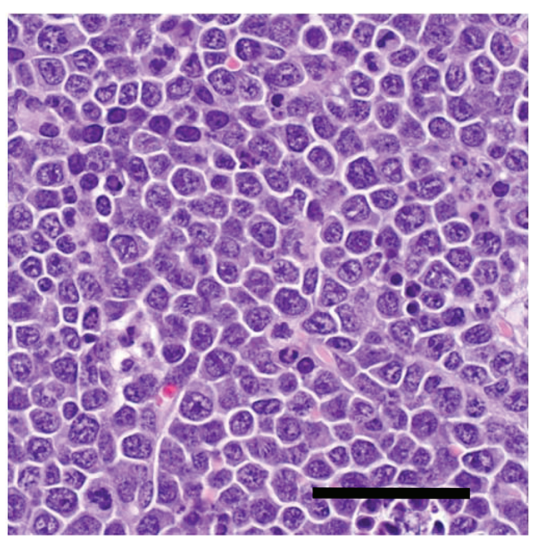

e. $\quad$ E $\mu-M y c 146 a^{-/-}$
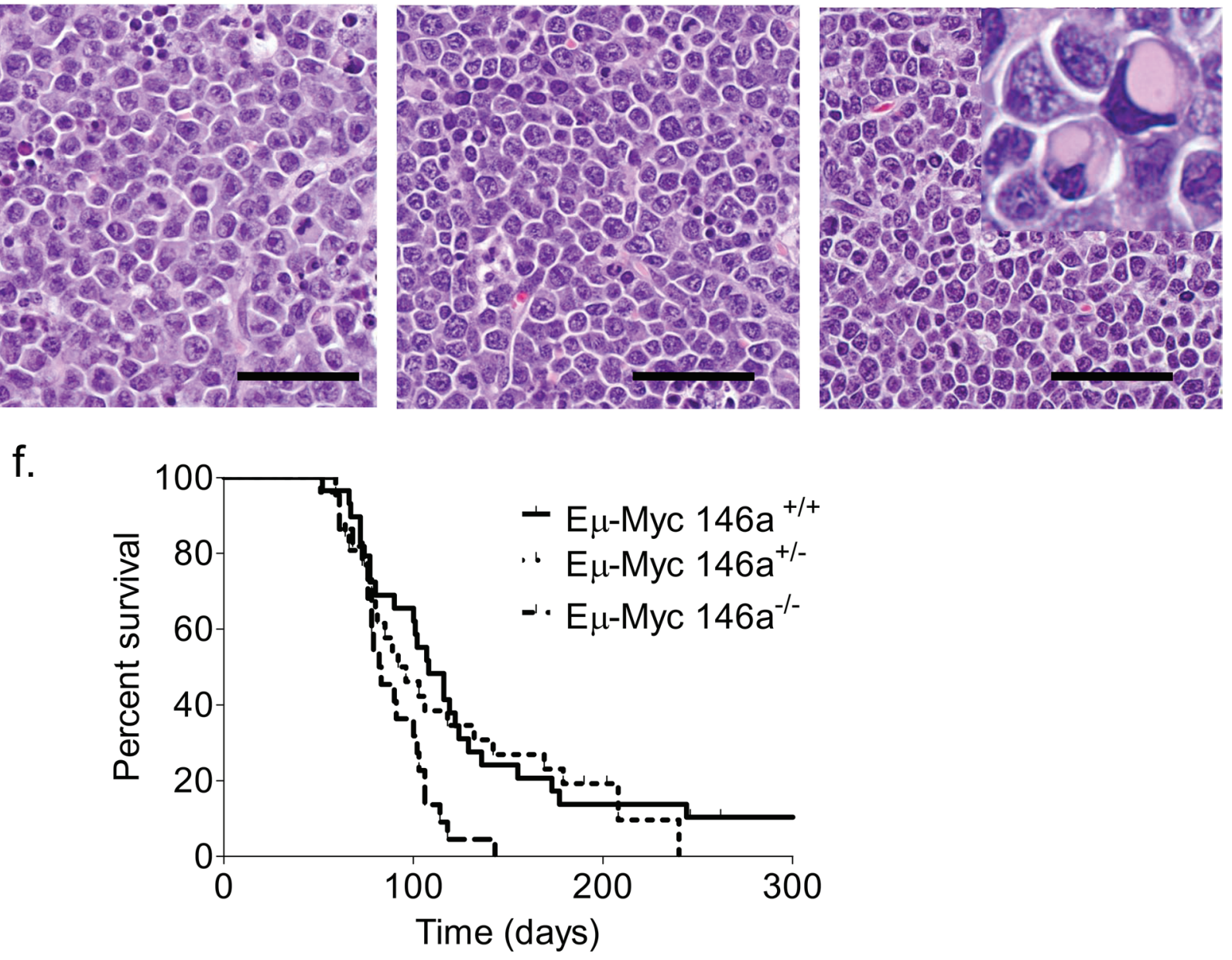

Figure 1: miR-146a deficiency causes increased mortality in E $\mu$-Myc mice. (a) RT-qPCR for c-Myc was performed on splenic

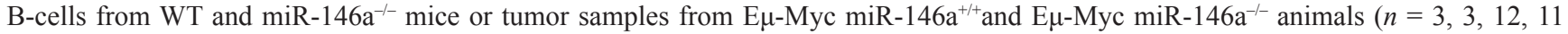
respectively) (nc: non-carrier; tg: transgene). (b) RT-qPCR for miR-146a was performed from the same samples as for c-Myc. (c-e) Hematoxylin and Eosin (H\&E) stained sections of lymph node tumors derived from E $\mu-\mathrm{Myc}$ miR-146a ${ }^{+/+}, \mathrm{E} \mu-\mathrm{Myc}$ miR-146a $\mathrm{a}^{+/}$and E $\mu-$ Myc miR-146a $\mathrm{a}^{--}$mice, respectively. The inset in (e) shows a subset of cells with immunoglobulin concretions. Scale bar for Figures $1 \mathrm{c}-\mathrm{e}, 40$ $\mu \mathrm{m}$. (f) Kaplan Meier survival curve of mice with E $\mu$-Myc oncogene and wild-type, heterozygous, or homozygous deficiency of miR-146a ( $n=26$ for E $\mu-M y c$ miR-146a ${ }^{+/+}$(Solid line in graph), $n=23$ for E $\mu-M y c$ miR-146a ${ }^{+/}$(Dotted line on graph), $n=22$ for E $\mu-M y c$ miR$146 \mathrm{a}^{-/}$(Dashed line on graph);w.t. vs. het comparison, Log-Rank Test, $p=0.6725$; w.t. vs. k.o. comparison, Log-Rank Test, $p=0.0027$ ). 


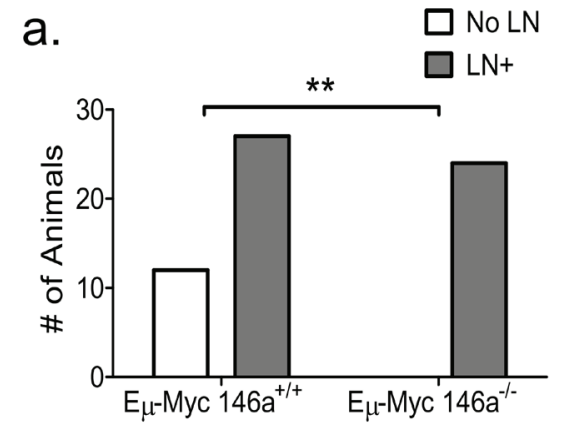

C.

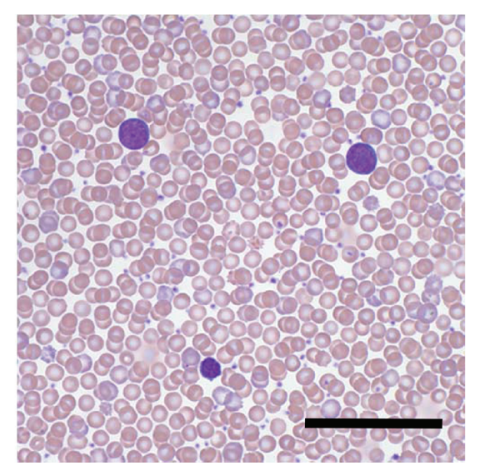

e.

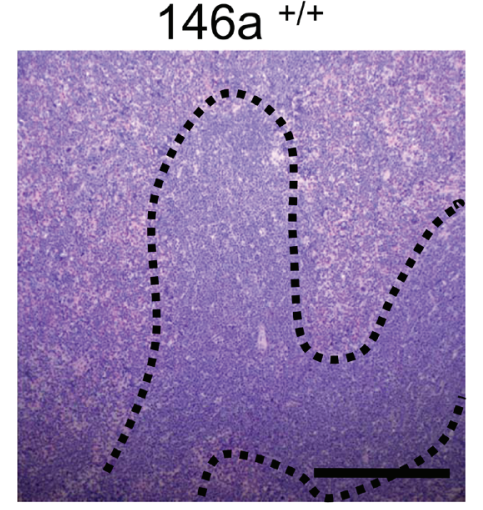

g.

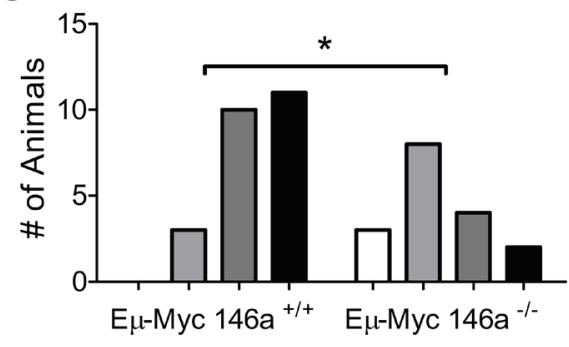

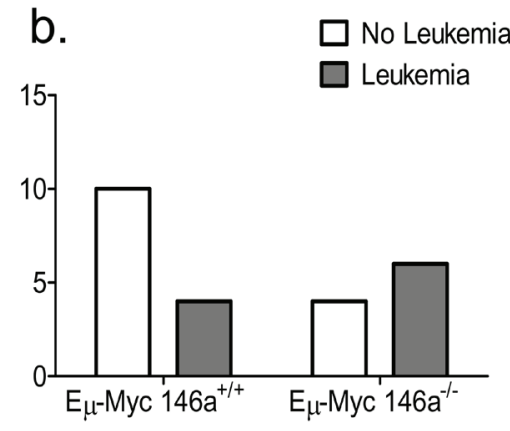

d.

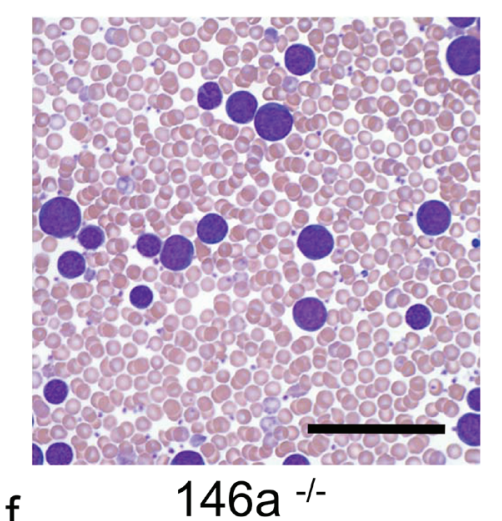

f.
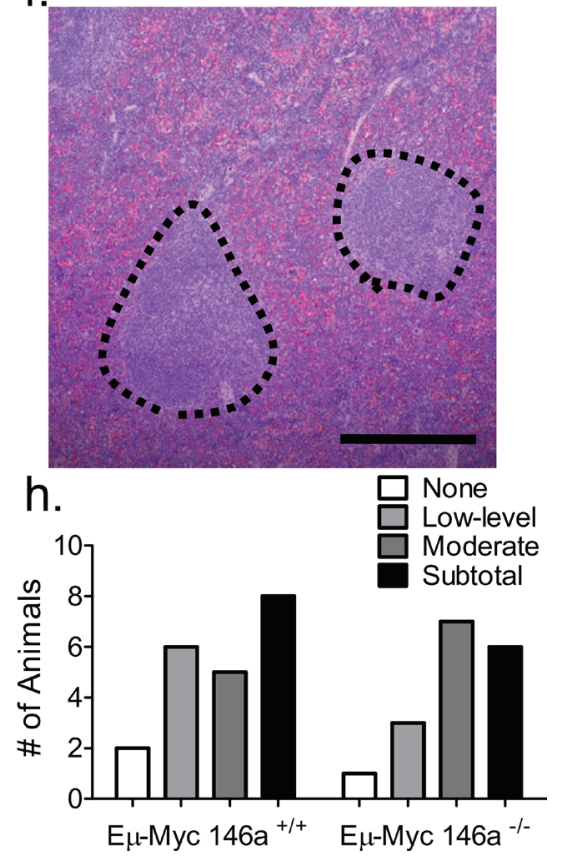

Figure 2: miR-146a-deficient tumors show a differential pattern of anatomic involvement. (a) Macroscopic lymph node

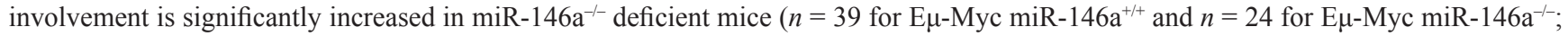
Fisher's exact test, $p=0.002$ ). (b) Quantitation of the incidence of leukemia, defined as a peripheral white blood cell count of greater than $30,000 / \mu \mathrm{L}$, in these mice, shows a trend towards statistical significance between the groups $\left(n=14\right.$ for E $\mu-\mathrm{Myc}$ miR-146a ${ }^{+/+}$and $n=10$ for E $\mu$-Myc miR-146a ${ }^{--}$; Fisher's exact test, $p=0.21$ ). (c-d) Wright stained peripheral blood smears from mice with miR-146a-sufficient and

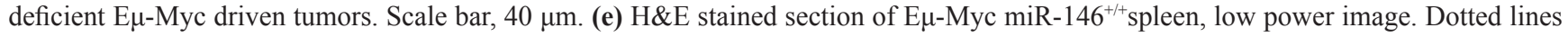
delineate expanded white pulp. Scale bar, $400 \mu \mathrm{m}$. (f) Low power view of an H\&E stained section showing relative sparing of the white

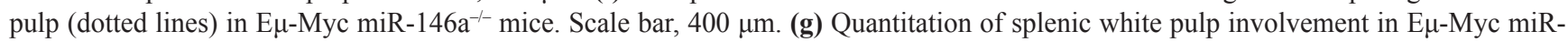
$146 \mathrm{a}^{+/}$and E $\mu-M y c$ miR-146a ${ }^{-1}$ mice on an ordinal 4-point scale going from no involvement to subtotal involvement of the spleen $(n=24$

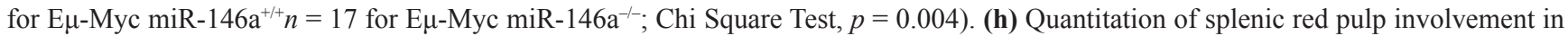
$\mathrm{E} \mu-\mathrm{Myc}$ miR-146a ${ }^{+/+}$and $\mathrm{E} \mu-\mathrm{Myc}$ miR-146a ${ }^{-/}$mice on an ordinal 4-point scale going from no involvement to subtotal involvement of the spleen $\left(n=24\right.$ for E $\mu-M y c$ miR-146a ${ }^{+/+} n=17$ for E $\mu$-Myc miR-146a ${ }^{-/}$; Chi Square Test, $\left.p=0.671\right)$. 
extensive involvement of the red pulp with relative sparing of the white pulp (Figure 2f). Using a semi-quantitative 4-point scale to grade involvement, we found that white pulp involvement was significantly higher in E $\mu-M y c$ miR-146a ${ }^{+/+}$mice compared to knockout mice (Figure $2 \mathrm{~g}$ ). Red pulp involvement was not different between the two groups (Figure $2 \mathrm{~h}$ ). Despite these differential patterns of involvement, the relative numbers of B-cells, T-cells and myeloid cells in the spleen were equivalent between the two groups of mice (Supplementary Figure 3d-3k). Together, the data suggest similar overall infiltration of the spleen (given similar weights and cellular composition), but a predilection for the red pulp when miR-146a is deficient, suggesting that the deficiency of miR-146a may change the homing properties of the malignant B-cells. The patterns of involvement are somewhat reminiscent of certain subtypes of B-cell lymphoma/leukemia that show peripheral blood involvement and red pulp involvement in the spleen, but are not correlated with NF- $\kappa \mathrm{B}$ activity or histologic subtype in humans.

\section{miR-146a-deficient tumors demonstrate a mature B-cell phenotype}

To further characterize the increased mortality seen in the miR-146a-deficient mice, we undertook immunophenotypic analyses. The tumors in both sets of mice were predominantly of B-cell phenotype (Figure 3a-3b). Similarly, E $\mu-M y c$ mice with a heterozygous deficiency for miR-146a also developed B-cell tumors (Supplementary Figure $4 a-4 d$ ). To examine the stage of differentiation, we examined expression of $\operatorname{IgM}$, finding that greater than $70 \%$ of tumors from E $\mu-M y c$ miR- $146 \mathrm{a}^{+/+}$ mice were IgM-. In contrast, only $42 \%$ of tumors from E $\mu-M y c$ miR-146a ${ }^{-/}$mice were IgM- (Figure 3c-3d). Amongst IgM- tumors, several were plasmacytic, shown by morphology and staining for CD138 (Figure 3e). Next, we dichotomized the data by mean fluorescent intensity (MFI), finding that CD138+ tumors were more frequently seen in the miR-146a-deficient background (Figure 3f). When we combined positivity for CD138 and IgM, most miR-146a-deficient tumors showed a mature B-cell phenotype (either IgM+ or CD138+) whereas miR146a-sufficient tumors were negative for both $\operatorname{IgM}$ and CD138 (Figure 3). Tumor cells from miR-146a-deficient mice showed lower expression of memory B-cell/ activation related antigen, CD80 (Supplementary Figure 4e-4f), but similar expression of CD44 (Supplementary Figure $4 \mathrm{~g}-4 \mathrm{~h}$ ). To further characterize the stage of B-cell differentiation in these tumors, we performed RT-qPCR to quantitate the expression of genes involved in B-cell differentiation. We found that transcripts for Blimp1, CD43, Bcl6 and Igh $\delta$ were all more highly expressed in tumors from miR-146a-deficient mice (Figure 3h-3k). Interestingly, female mice, which showed a statistically significant difference in survival, showed similar trends in their immunophenotypic profiles (Supplementary Figure $5 \mathrm{a}-5 \mathrm{f}$ ) as well as in gene expression of maturation-related B-cell transcripts (Supplementary Figure $5 \mathrm{~g}-5 \mathrm{j}$ ) when compared to the group overall. Together these findings indicate that miR-146a-deficient tumors are composed of malignant B-cells that derive from a different stage of differentiation than tumors sufficient for miR-146a.

\section{miR-146a-deficient tumors show a limited difference in transcriptome expression, including many putative targets of miR-146a}

To define a mechanistic basis for miR-146a-deficient B-lymphomagenesis, we performed RNA-sequencing on four miR-146a sufficient and two miR-146a-deficient tumors. Based on this comparison, we arrived at a list of 249 genes that were differentially regulated with an adjusted $p$-value of 0.05 or lower (Figure $4 a$ ). We then searched the dataset for miR-146a targets predicted by TargetScan $[2,3]$. Of the differentially regulated genes, 53 genes are predicted to be miR-146a targets (Figure $4 b$ ). When we examined the genes that were upregulated, 29 out of 140 genes were predicted miR-146a targets (Figure $4 \mathrm{c}$ ), and this did not represent a statistical enrichment. Next, we confirmed some of the findings by RT-qPCR in the larger set of tumor samples that we had collected. Four of the top ten genes from RNA sequencing had significantly different expression levels in the tumors when assayed by qPCR. These genes include Jhy and Camk2b (Figure 4d and 4f). Jhy is a recently described novel gene with no known function in oncogenesis or hematopoiesis; while Camk2b has a previously described putative role in epithelial cancer [24]. The gene Dtx3, which showed differential regulation by RNA-sequencing, was not differentially expressed in the larger set of tumor samples (Figure 4h). Other genes that were differentially expressed included the putative target Egrl, with Nrp2 showing a trend towards differential expression (Figure $4 \mathrm{e}$ and $4 \mathrm{~g}$ ). A third predicted target, Axl, failed to show differential regulation by $\mathrm{qPCR}$ in this larger set of samples (Figure 4i). Hence, the transcriptome data provided us with a starting point for understanding tumorigenesis, uncovering putative miR-146a targets in the setting of B-cell oncogenesis.

\section{The transcriptome regulated by EGR1 is differentially regulated in miR-146a-deficient tumors}

The early growth response-1 gene (Egrl), has previously described functions in hematopoietic differentiation [25, 26]. Given that Egrl is overexpressed in miR-146a-deficient tumors, we undertook an analysis to determine whether the Egrl transcriptome is differentially regulated. Using a publically available ChIP-Seq dataset, we gathered a list of EGR1 transcription factor binding 
a.
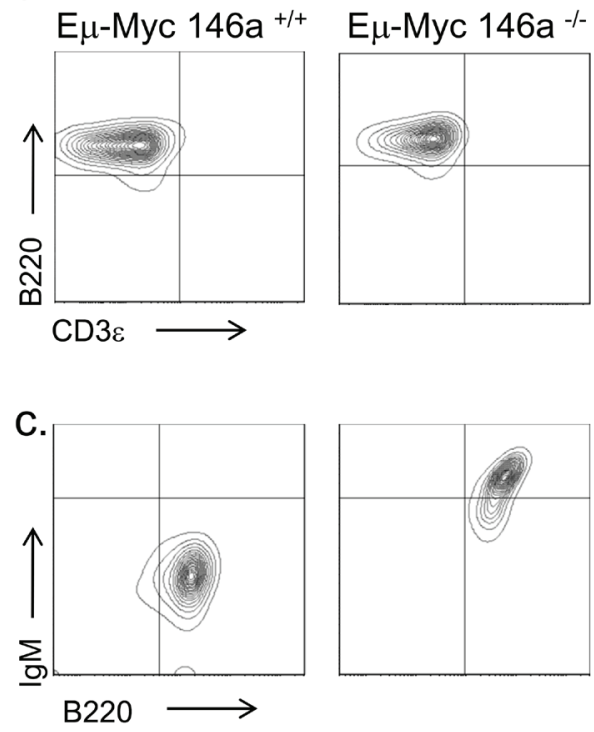

e.
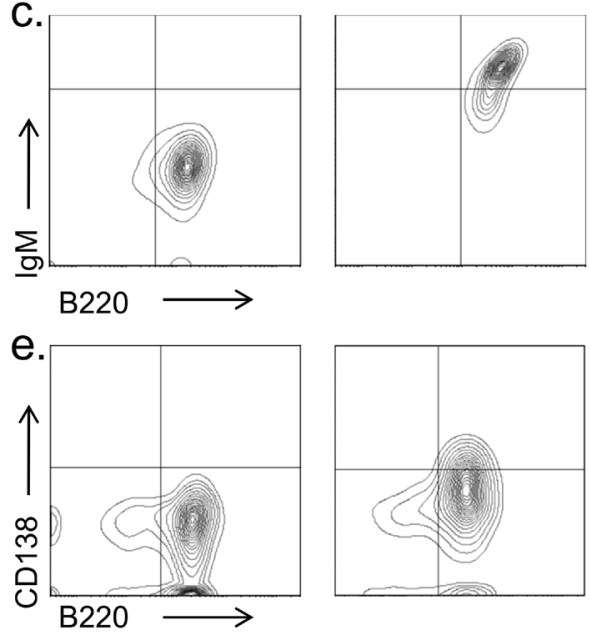

b.

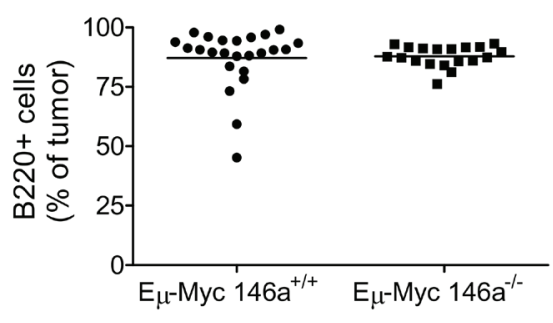

d.

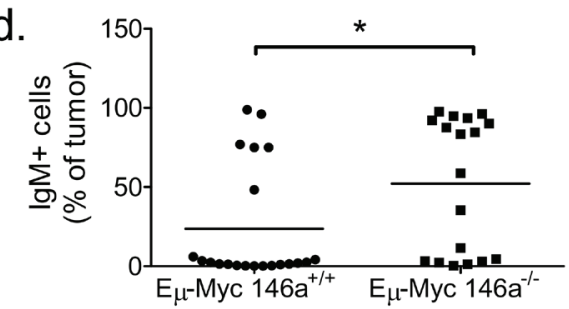

f.

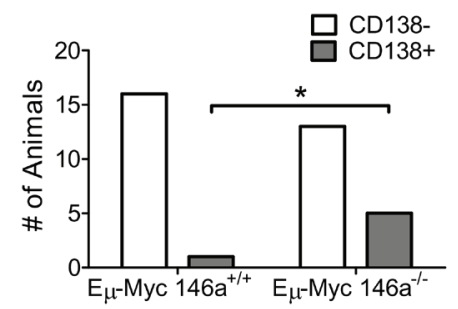

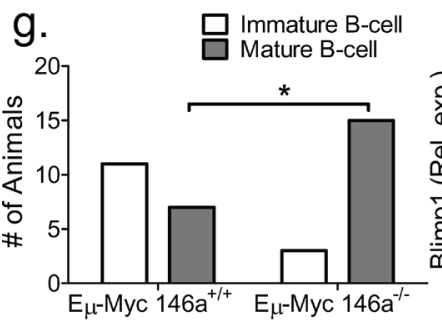
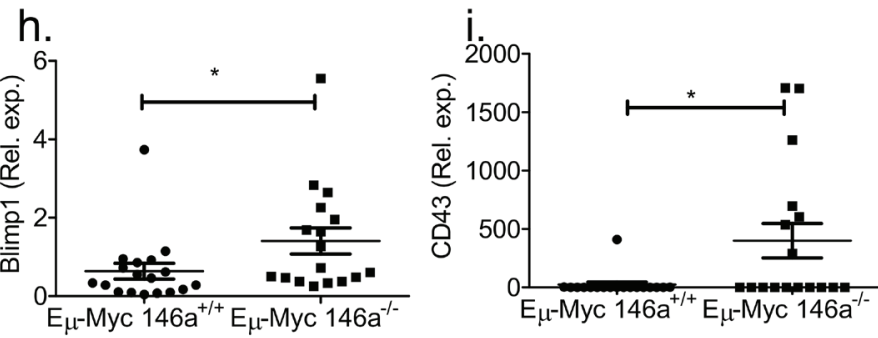

j.

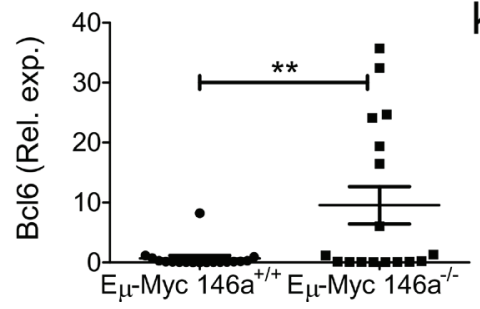

$\mathrm{k}$.

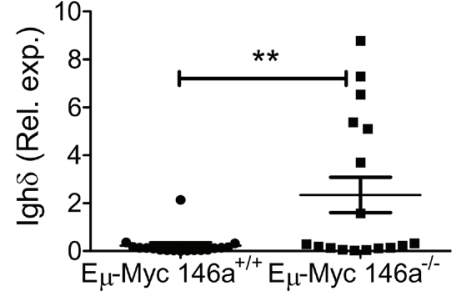

Figure 3: miR-146a deficiency causes a mature B-cell phenotype in E $\mu$-Myc mice. (a) Representative FACS plot showing

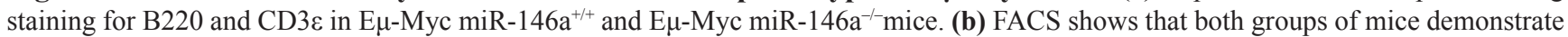

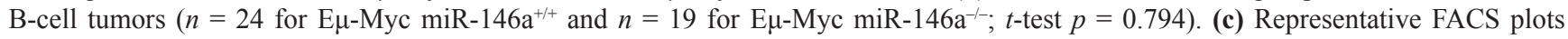
stained for B220 and IgM from tumors derived from E $\mu-M y c ~ m i R-146 \mathrm{a}^{+/ /}$and $\mathrm{E} \mu-\mathrm{Myc}$ miR-146a $\mathrm{a}^{-/}$mice. (d) Percentage of IgM positive cells in tumors from both cohorts showing increased IgM positivity in E $\mu$-Myc miR-146a ${ }^{-/}$tumors $\left(n=25\right.$ for E $\mu$-Myc miR-146a $\mathrm{a}^{+/ /}$and $n=17$ for E $\mu$-Myc miR-146a ${ }^{-/} ; t$-test, $p=0.03$ ). (e) Representative FACS plots stained for B220 and CD138 from tumors derived from E $\mu$ Myc miR-146a $\mathrm{a}^{++}$and E $\mu-M y c$ miR-146a ${ }^{-/}$mice. (f) Dichotomized CD138 expression data (see methods for details on dichotomization), showing animals with CD138+ versus CD138- tumors $\left(n=18\right.$ for E $\mu$-Myc miR-146a ${ }^{+/+}$and $n=18$ for E $\mu$-Myc miR-146a ${ }^{-/}$; Chi-square test, one-sided $p=0.04$ ). (g) Tumors were dichotomized as being either immature (double negative for CD138 and IgM) or mature (having

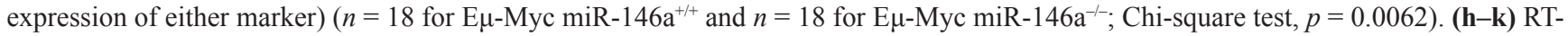

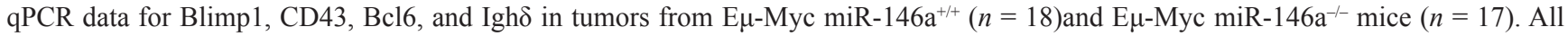
comparisons showed statistically significant differences by $T$-test $(p=0.05$ for Blimp1 (h), $p=0.014$ for CD43 (i), $p=0.0070$ for Bcl6 (j), and $p=0.0067$ for $\operatorname{Igh} \delta(\mathrm{k})$. 

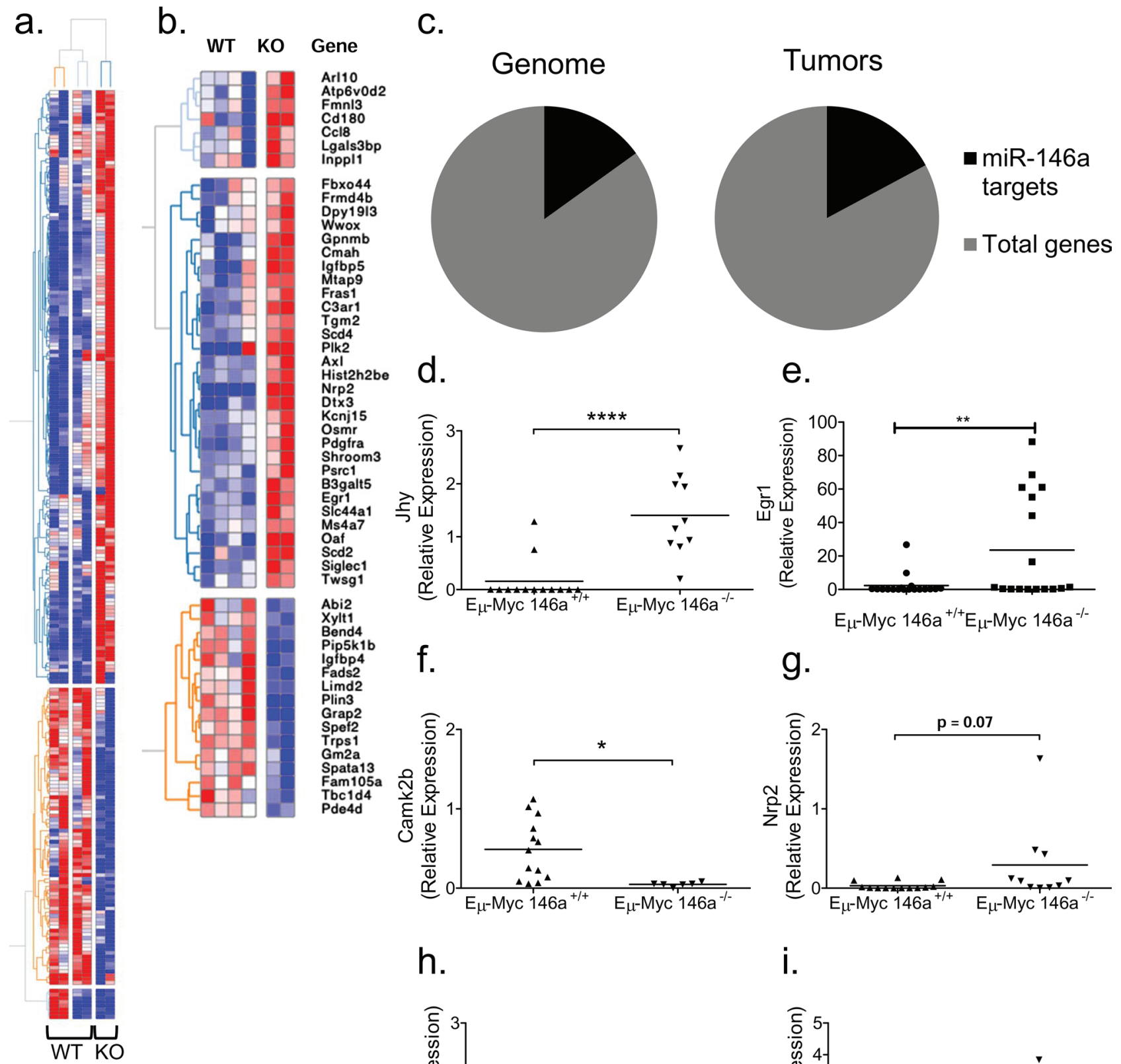

h.

i.
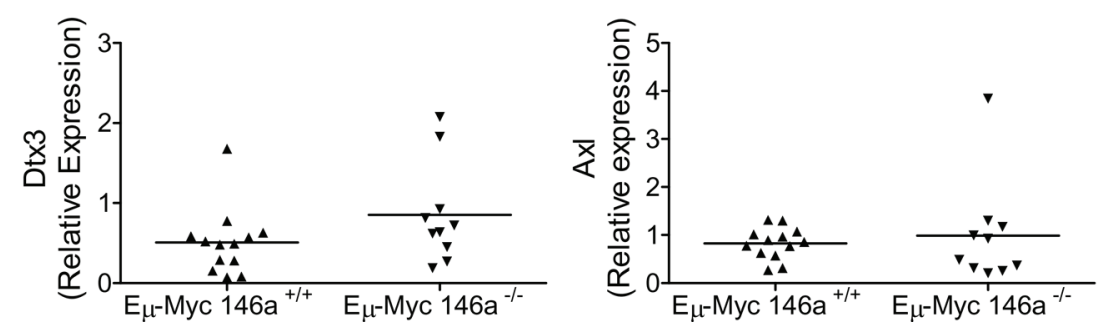

Figure 4: Gene expression analyses of $\mathrm{E} \mu-\mathrm{Myc}$ driven tumors with miR-146a deficiency. (a) Genes differentially expressed between E $\mu-M y c$ miR-146a ${ }^{+/+}$and E $\mu-M y c$ miR-146a ${ }^{-/}$tumors. (b) Differentially expressed genes with miR-146a sites in their UTR as predicted by the TargetScan algorithm. The heat map color scale represents, for each gene, the relative expression level using the average mean gene expression as a reference. (c) Graphical representation of the percentage of the genome (left) predicted to be targeted by miR146a (2773 predicted targets out of 18, 393 annotated UTRs), compared with the percentage of upregulated genes in the tumor dataset (right) that are predicted miR-146a targets (29 predicted targets out of 169 upregulated genes). No statistically significant enrichment was found (Chi-square test). (d-i) RT-qPCR of genes found to be differentially regulated by RNA-sequencing analysis, including $J h y$ (d; $t$-test, $p<0.0001$ ), Egrl (e; $t$-test, $p=0.0086$ ), Camk2b (f; $t$-test, $p=0.01$ ), Nrp2 (g; $t$-test, $p=0.0743$ ), Dtx3 (h; $t$-test, $p=0.127$ ) and $A x l$ (i; $t$-test, $p=0.616)$. The three genes on the left (Jhy, Camk2b and Dtx3) were amongst the most differentially regulated genes between the miR-146a sufficient and deficient tumors by RNA sequencing. The three genes on the right (Egrl, Nrp2 and Axl) represent putative targets of miR146a (For RT-qPCR analysis $n=13$ for E $\mu$-Myc miR-146a ${ }^{++}$and $n=10$ for E $\mu-M y c$ miR-146a ${ }^{-1-}$ for panels d, g, h, i; $n=13$ for E $\mu-M y c$

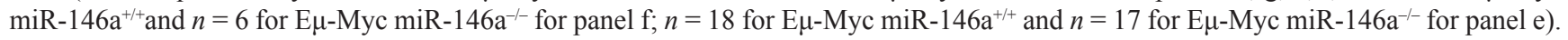


a.

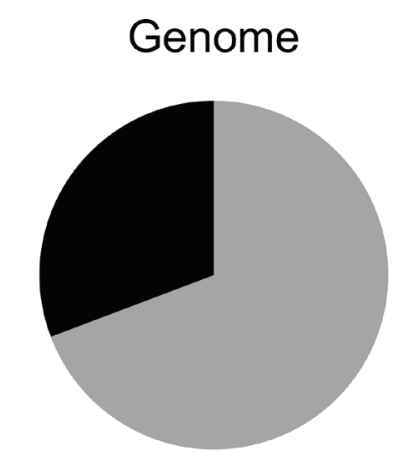

b.

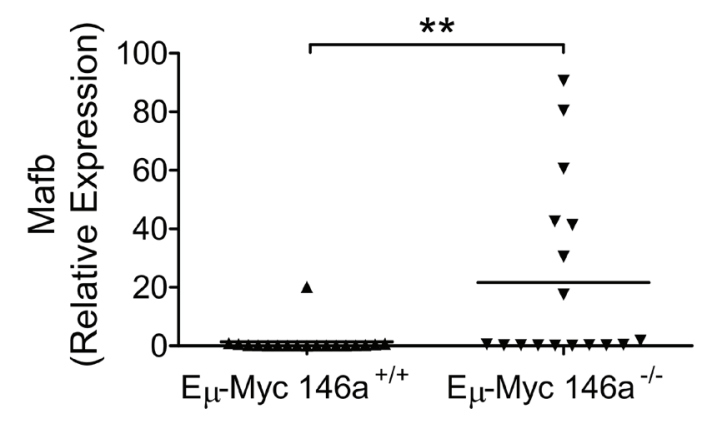

d.

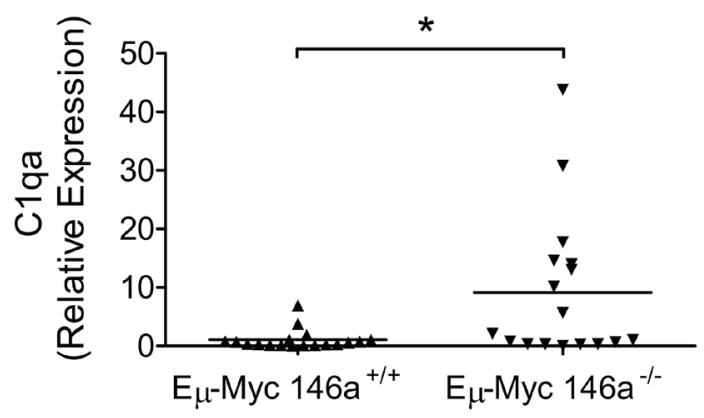

f.

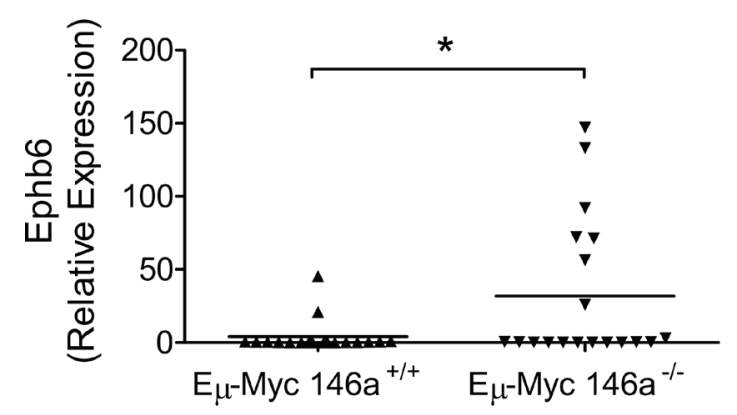

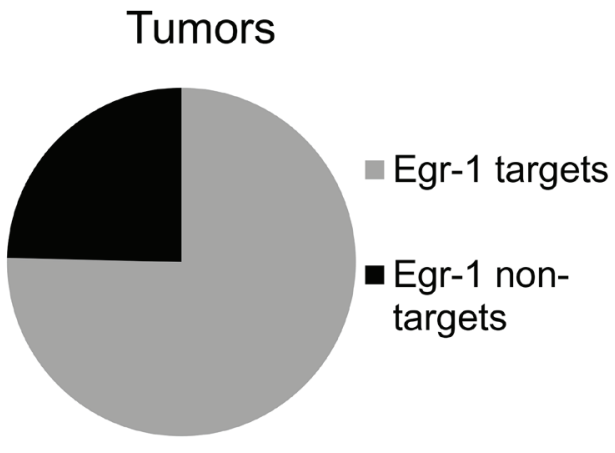

C.

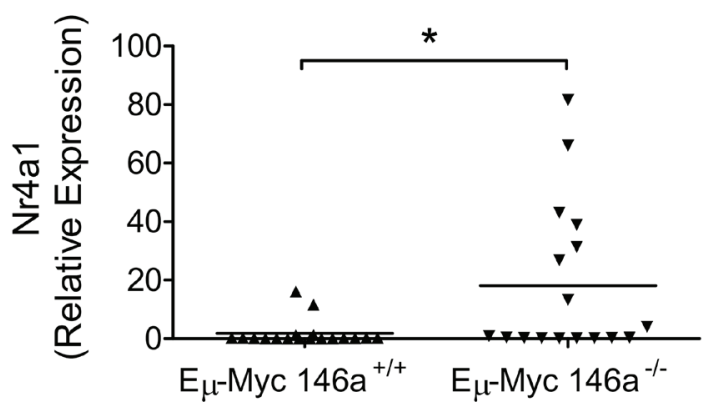

e.

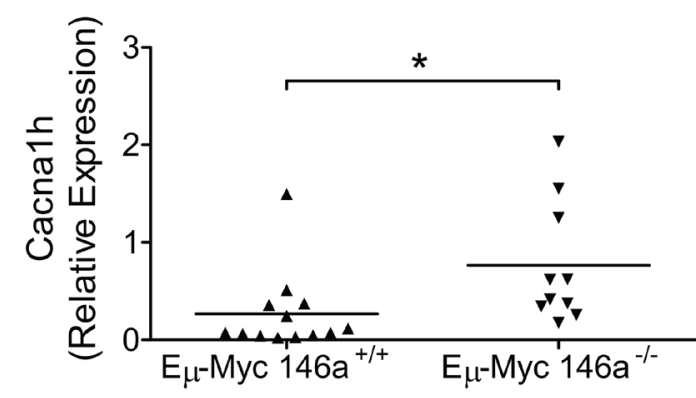

g.

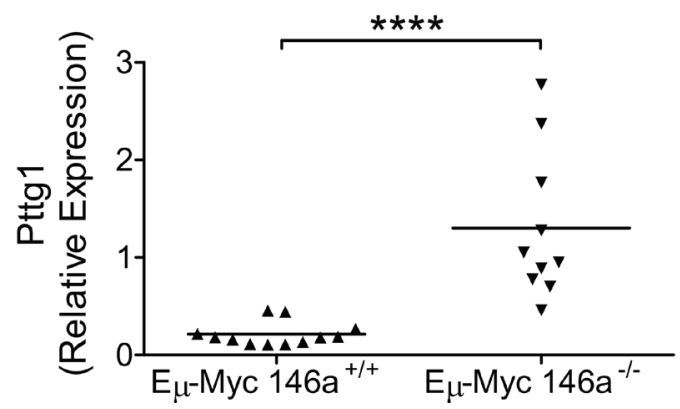

Figure 5: Genes with EGR1 transcription factor binding sites are enriched in E $\mu$-Myc driven tumors with miR-146a deficiency. (a) Graphical representation of the percentage of the genome (left) containing EGR1 TFBS (11136 TFBS out of 16288 genes that were conserved between human and mouse), compared with the percentage of differentially regulated genes in the tumor dataset (right) that show EGR1 TFBS (153 with TFBS out of 203 differentially regulated genes that are conserved between mouse and human). This difference was found to be statistically significant (Chi-square test, one-sided $p=0.0353$ ). (b-g) RT-qPCR confirmation of differentially regulated genes that show EGR1 TFBS, including Mafb (b; $t$-test, $p=0.0093), N r 4 a 1$ (c, $t$-test, $p=0.0126), C l q a$ (d; $t$-test, $p=.0101$ ), Cacnal $h$ (e; $t$-test, $p=.0308$ ), Ephb6 (f; $t$-test, $p=.0248$ ), Pttgl (g; $t$-test, $p<0.0001$ ). For these RT-qPCR analyses, $n=18$ for E $\mu$-Myc $\operatorname{miR}-146 \mathrm{a}^{+/+}$and $n=17$ for E $\mu$-Myc miR-146a $\mathrm{a}^{-/}$. 
sites (TFBS) around known protein coding genes in three different human cell lines (K562, GM12878, and H1-hESC) [27]. This dataset was compared to the list of differentially regulated genes in miR-146a-deficient tumors that have human homologs (Supplementary Figure 6a-6b). Remarkably, genes that show TFBS for EGR1 were statistically overrepresented in the differentially regulated gene set from miR-146a-deficient tumors (Figure 5a). We then confirmed several targets of EGR1 that (i) were differentially regulated in the RNA-sequencing dataset and (ii)had been previously shown in the literature to be EGR1 targets or had EGR1 binding sites based on the ChIP-Seq datasets. Several genes that are important in hematopoiesis and/or cancer were profiled in the larger set of tumors and showed a significantly differential regulation. These genes included Mafb (Figure 5b), Nr4al (Figure 5c), Clqa (Figure 5d), Cacnal $h$ (Figure 5e), Ephb6 (Figure 5f) and Pttgl (Figure 5g and Supplementary Figure 6c). Changes in gene expression in Egr1 and a subset of its targets were conserved in the subset of tumors derived from female mice, hinting that these molecular changes may underlie the increased lethality in the knockout mice (Supplementary Figure $5 \mathrm{k}-5 \mathrm{n}$ ). Together, these findings indicate that miR146a-regulated Egrl may represent a critical target that leads to the elaboration of a gene expression signature and the more aggressive phenotype observed during miR-146adeficient, E $\mu$-Myc-mediated oncogenesis.

\section{Egr1 is regulated by miR-146a and overexpression of miR-146a has an anti-growth effect on B-cell lymphoma cell lines}

To elucidate whether miR-146a targets Egrl, we examined the 3' untranslated region (UTR) of the cDNA transcript. In the human EGRl sequence, there is a miR146a 7-mer binding site located at position $111-117$ of the 3' UTR (Figure 6a). The DNA sequence surrounding this area is somewhat conserved between the human and the mouse, but the complete 7-mer site is not present in the mouse (Supplementary Figure 6d). To examine direct targeting, we cloned a 996 bp segment of the human EGR1 3'UTR into the pmiRGlo vector. Co-transfection of a miR-146a over- expression vector along with the luciferase-EGRI 3'UTR fusion construct showed significant repression of luciferase activity, compared to the empty vector, similar to that observed for Traf6. Mutation of the binding site for miR-146a in the EGR1 3' UTR derepressed luciferase expression. A similar repression was not consistently observed for the murine Egr1 3'UTR (Figure 6b). Stable overexpression of miR-146a using a retroviral vector in the murine leukemia cell lines, 70Z/3 and WEHI-231 led to a repression of Egrl at both the transcript and protein levels (Figure 6c-6e, 6i-6j, 6l). In addition, overexpression of miR-146a led to decreased growth of both cell lines at baseline and following serum starvation (Figure $6 \mathrm{f}-6 \mathrm{~g}, 6 \mathrm{~m}-$ $6 \mathrm{n})$. Moreover, we observed repression of the EGR1 target,
Nr4al (Figure 6h, 6k), implicating the same sequence of regulation with miR-146a overexpression as that observed with miR-146a deficiency in the tumors. Moreover, miR146a overexpressing cells showed a downregulation of Blimp1 and Bcl6 (Supplementary Figure 6i-61), in line with the observations made in the tumors. In the human DLBCL cell line, SUDHL2, miR-146a overexpression led to repression of EGR1 as well as the expected target of miR-146a, TRAF6 (Figure 6o). Nrp2 was validated as an additional target of miR-146a (Supplementary Figure $6 \mathrm{e}-6 \mathrm{~h})$. These findings imply a role for miR-146a in the regulation of B-cell leukemia/lymphoma cell growth and demonstrate that in the human, miR-146a directly targets EGR1 via canonical 3' UTR-mediated targeting. Hence, miR-146a overexpression and knockout results in significant effects on Egrl and downstream gene expression, suggesting a conserved regulatory module in the human and mouse.

\section{DISCUSSION}

In this manuscript we describe the modulation of tumorigenesis by the NF- $\mathrm{KB}$ induced tumor suppressor microRNA, miR-146a. miR-146a plays a very important role in immune cells and seems to be critical in modulating feedback inhibition of the NF-кB pathway. Its role in T-cells, myeloid cells and hematopoietic stem cells is well-established, with deletion of this miRNA leading to T-cell hyper activation, myeloid hyperplasia and tumors, and stem cell exhaustion $[9,11,14,16]$. The role of miR146a in the developmental sequence of B-cells is less understood. In young miR-146a-deficient mice, B-cell development appears to proceed normally, but by the age of six months, lymphoid follicles in the spleen and other lymphoid tissue demonstrate hyperplasia $[9,28]$. Following this phase, myeloproliferative disease becomes the dominant phenotype and B-cell numbers drop as the mice age. Nonetheless, aged miR-146a-deficient mice show an increased incidence of B-cell malignancies. Interestingly, these tumors show a predilection for the lymph nodes, similar to what we have observed here with E $\mu$-Myc driven tumors.

miR-146a-deficient E $\mu-M y c$ transgenic mice develop mature B-cell neoplasms with IgM and/or CD138 expression, leading to a higher proportion of lymph node tumors and leukemia in the peripheral blood. There is some heterogeneity in the proportion of E $\mu$-Myc mice reported to develop IgM+tumors in the literature [29,30], but our results have been consistently in the $20-30 \%$ range. The immunophenotypic differences, along with concordant gene expression changes (e.g., Blimp1 and Bcl6), indicate that miR-146a deficiency may alter the stage of B-cell development that is most susceptible to transformation by $c-M y c$. This is an interesting observation as B-cell neoplasms in humans that have increased levels of $c-M y c$ can also derive from different stages of development (for example, B-lymphoblastic leukemia, Burkitt's lymphoma, 
a.

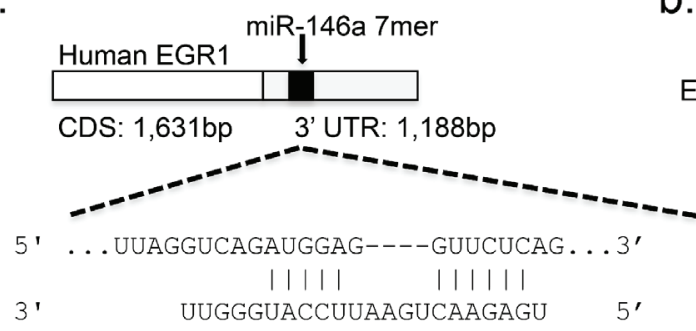

C.

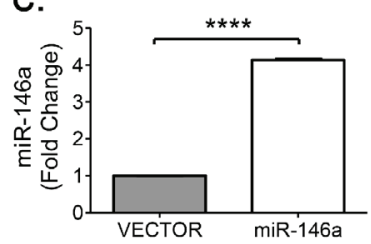

f.

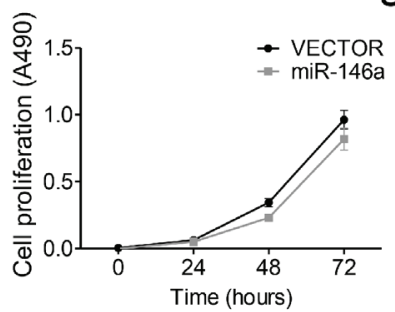

i.

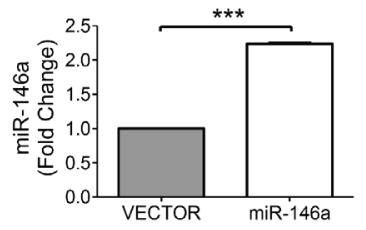

d.

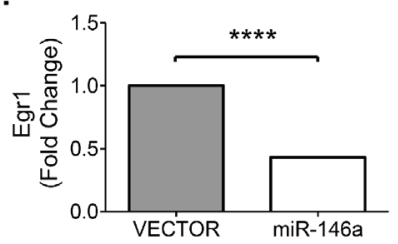

g.

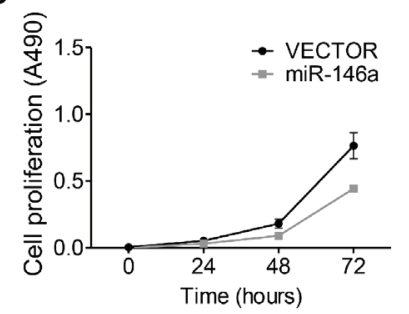

j.

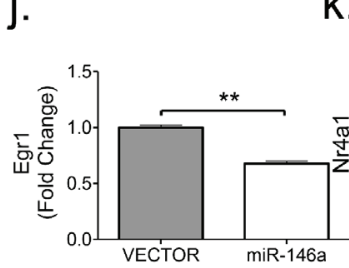

b. 3'UTR:

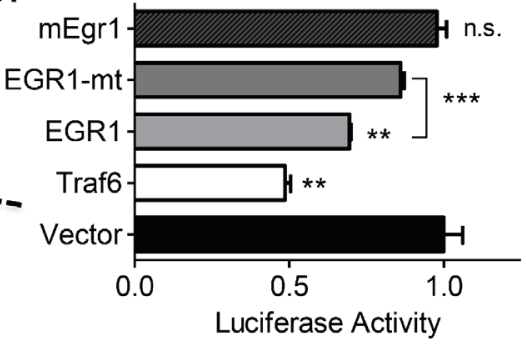

e.

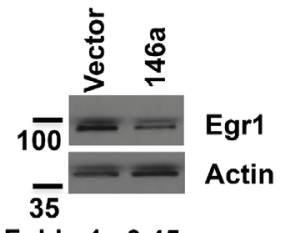

h.

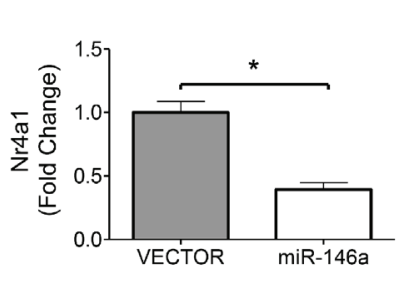

$\mathrm{k}$.

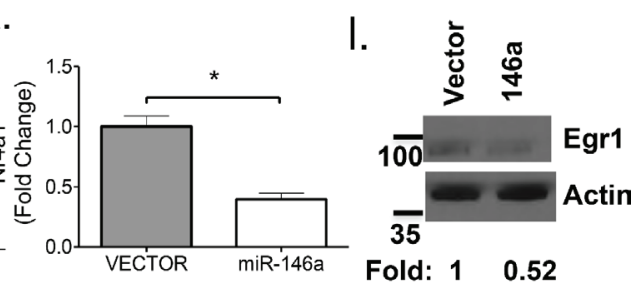

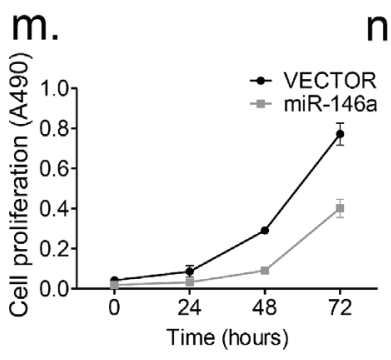

n.

o.
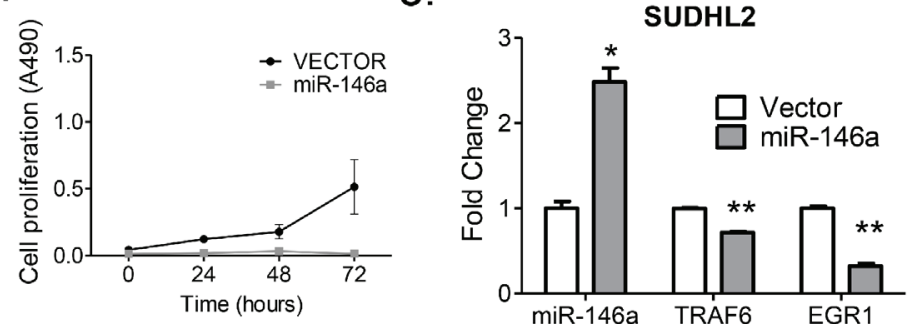

Figure 6: Egr1 is regulated by miR-146a. (a) The human EGR1 cDNA contains a 1, 188 bp 3'UTR that contains an intact miR-146a 7-mer binding site. Shown is a schematic of the binding between EGR1 and miR-146a. (b) Luciferase assays quantitating repression with MGP/miR-146a co-transfection relative to MGP alone for each of the UTRs depicted. Each measurement is representative of firefly luciferase normalized to renilla luciferase, and was performed in duplicate, with the experiment was repeated at least three times ( $T$-test; Traf6 v Vector, $p=0.0013$; EGR1 vs. vector, $p=0.0077$; EGR1 vs. mutant EGR1, $p=0.0002$ ). (c-d) RT-qPCR analyses of miR-146a and Egrl, respectively in the murine 70Z/3 cell line. (e) Western Blot analysis confirms EGR1 repression with miR-146a over expression in the 70Z/3 cell line. Fold repression was computed using ImageJ software. (f-g). Cell proliferation (MTS) assays were performed using $70 \mathrm{Z} / 3$ cells transduced with either empty vector (MGP) or miR-146a over expressing vector (MGP-miR-146a). Basal growth is shown in (f), while growth in samples following 24 hours of serum starvation is shown in (g). (h) RT-qPCR of the EGR1 target gene, Nr4al, shows repression in miR-146a overexpressing cells. (i-k). RT-qPCR analyses of miR-146a, Egrl and Nr4al, respectively, in the murine WEHI231 cell line. (l) Western Blot analysis, as in (e), using the WEHI-231 cell line (m-n). Cell proliferation (MTS) assays were used to measure basal growth and growth following 4 hours of serum starvation (o) miR-146a overexpression in a human DLBCL cell line, SUDHL2 results in the repression of TRAF6 and EGR1. All comparisons were made with $T$-test for Figure 6c-o, with the following legend: ${ }^{*} p<0.05$; $* * p<0.005 ; * * * p<0.0005 ; * * * * p<0.0001$. 
DLBCL, and plasma cell myeloma) [31-35]. Here, the expression of a miRNA in an experimental model of Myc-mediated oncogenesis does alter the stage of B-cell oncogenesis. Although the relevance to human disease remains to be established, it is interesting to speculate that miRNA expression may have an important role in defining the cellular composition of lymphoma from a given driver mutation.

An important question raised by this study is whether the observed phenotypes occur as a consequence of cellintrinsic or cell-extrinsic mechanisms. The primary tumor sites showed primarily B-cells, and histologically, the tumors appeared to be quite homogeneous. In miR-146adeficient mice, T-cell activation is thought to occur as a consequence of repeated bouts of subclinical infection and inflammation without the "recalibrating" effects of miR146a expression. We do not think this is a likely cause for the augmentation of oncogenesis, since the development of tumors under specific pathogen free conditions do not occur early in life in miR-146a singly-deficient mice. Heterozygotes did not show increased mortality in the presence of E $\mu-\mathrm{Myc}$, whereas miR-146a heterozygosity alone causes inflammatory changes [9]. Hence, it is likely that increased tumorigenesis in our mice occurs primarily as a consequence of B-cell intrinsic mechanisms. However, we cannot entirely exclude a cell-extrinsic process driven by benign but hyperactivated T-cells. Future studies to address this issue will include producing B-cell specific knockouts and knock-ins of miR-146a to study disease progression, but are beyond the scope of the current study.

In an effort to further characterize tumorigenesis in these mice, we undertook gene expression analysis by high-throughput sequencing. We have found that a small set of genes are significantly differentially regulated between miR-146a sufficient and deficient E $\mu$-Myc tumors. While the functional analysis did not reveal an overall pattern to the differentially regulated gene set, the individual genes do seem to be important in various aspects of tumorigenesis (Supplementary Table 2) [36, 37]. Amongst the differentially regulated genes, many have roles in oncogenesis and B-cell development. Perhaps the most interesting gene to be identified by our analysis is Egr1, a factor known to promote differentiation in the hematopoietic lineage. EGR1 transcriptionally induces a range of genes, and the differentially regulated gene set in miR-146a-deficient mice was enriched for these targets. Indeed, some of the most differentially regulated genes in our dataset were previously described targets of EGR1 or putative targets as defined by the presence of transcription factor binding sites. Critically, miR-146a regulates Egr1, and provides an explanation for the observed phenotypic differences in the tumors from these mice. However, we must note that direct targeting was only seen with the human EGR1 3'UTR, and hence the mechanism of this regulation in the mouse may be indirect. This could include non-canonical mechanisms of miRNA targeting (such as in the 5'UTR) and/or indirect regulation.
miR-146a overexpression changes the growth of murine B-cell lines, suggesting the importance of the EGR1-mediated transcription program in maintaining growth of these cells. Notably, miR-146a overexpression also led to the repression of certain mRNAs that are important in B-cell differentiation including Blimp1 and Bcl6, once again supporting the notion of miR-146a playing a role in the maturation stage of the tumor cells. This is line with prior reports showing that expression of an Egr1 transgene supported the development of progenitor cells into mature, IgM-expressing B-cells [26]. Interestingly, some of the genes that contain TFBS for EGR1 are also regulated by miR-146a (for example, Nrp2), suggesting that miR-146a may target several points in the same pathway during B-cell oncogenesis. Downstream, genes without a defined role in B-cell neoplasms were also identified. Pttgl is overexpressed in a wide variety of endocrine and non-endocrine tumors, modulates tumor invasiveness and recurrence in several systems, and has functions in chromatid separation and cell cycle progression [38]. Jhy is another gene we identified whose deficiency causes juvenile hydrocephalus in mice [39]. It will be of great interest to study how miR-146a deficiency causes differential regulation of these novel genes and what their roles are in normal and malignant B-lymphopoiesis.

Our findings also point to the cell-type specific nature of miRNA mediated regulation. The targets uncovered in a malignant B-cell are different than those found in an activated T-cell or a myeloid cell. For example, our findings suggest that Traf6 and Irak1, which are highly important in the elaboration of myeloid phenotypes, may not be as important in B-cell oncogenesis, particularly that induced by $c-M y c$, as these genes were not differentially regulated in the tumors that we examined (data not shown). These findings highlight the need for experimental work in carefully defined physiological and pathological systems to comprehensively understand miRNA function.

In summary, we show that concurrent $c-M y c$ overexpression coupled with the absence of a bona fide tumor suppressor miRNA leads to more aggressive tumor due to a small set of genes that are regulated directly or indirectly by miR-146a. . Our novel set of targets may indicate that miR-146a regulates components of signaling networks other than the NF- $\kappa$ B inflammatory pathway. Hence, our work opens the door to new areas of investigation in B-cell oncogenesis and miRNA biology.

\section{MATERIALS AND METHODS}

\section{Mice}

miR-146a-deficient (miR-146a $\mathrm{a}^{-/}$) mice were developed as previously described $[9,11,16]$. E $\mu-M y c$ mice were purchased from Jackson laboratories and housed under pathogen free conditions at the University of California, Los Angeles [40]. E $\mu-M y c$ and miR-146a ${ }^{-/}$mice 
were bred to obtain $\mathrm{E} \mu-\mathrm{Myc}$ miR-146a $\mathrm{a}^{+/}$mice with further miR-146a ${ }^{-/-}$intercross producing E $\mu$-Myc miR-146a ${ }^{-/-}$ mice. Mice were monitored for tumors and sacrificed when they became pre-moribund indicated by the following criteria: tumors larger than $1.5 \mathrm{~cm}$, emaciation, or any other signs of distress. All mouse studies were approved by the UCLA Office of Animal Research Oversight.

\section{Flow cytometry}

Blood, bone marrow, spleen, and lymph node tumors were collected from the mice under sterile conditions. Single cell suspensions were lysed in red blood cell lysis buffer. Fluorochrome conjugated antibodies against B220, CD3e, CD11b, Ter119, CD19, IgM, CD80, CD138, CD44, CD21, CD23, and CD5 were used for staining (all antibodies obtained from Biolegend). Flow cytometry was performed on a FACSAria and analysis performed using FlowJo software. Dichotomization of flow cytometric measurements was accomplished by visual inspection of the data and identification of clusters within the data. These were then validated by comparison of the means and averages of the two clusters. For CD138, this was accomplished by examining the Mean Fluorescence Intensity and determining that the low expression cluster had a mean MFI, $154.0 \pm$ $13.96(N=30)$ and $557.6 \pm 71.87(N=7)$ for the high CD138 samples ( $p<0.0001$ for this comparison).

\section{Histopathology}

Organs were collected after necropsy and fixed in $10 \%$ neutral buffered formalin. These were then embedded in paraffin, processed for hematoxylin and eosin staining by the Translational Pathology Core Laboratory at UCLA. Histopathologic analysis was performed by a board certified hematopathologist (D.S.R). The degree of splenic involvement was scored on a 4-point scale for red and white pulp involvement. Analysis of dichotomized or ordinal-type histopathologic data was accomplished by the use of Fisher's Exact Test.

\section{Statistical analyses}

Figures are graphed as mean with the standard deviation of the mean (SD) for continuous numerical data. Bar graphs are employed to show dichotomized or ordinaltype histopathologic data. Student's $t$-test, Fisher's exact test, Chi square test, and Kaplan-Meier survival analysis were performed using GraphPad Prism software, applied to each experiment as described in the figure legends.

\section{RNA-sequencing and analysis}

Total RNA was extracted from tumors using Trizol combined with Qiagen miRNEasy mini kit with additional on column DNAse I digestion. Following isolation of RNA, cDNA libraries were built using the
Illumina(San Diego, CA) TrueSeq RNA Sample Preparation kit V2 (RS-122-2001). An Agilent Bioanalyzer was used to determine RNA quality ( $\mathrm{RIN}>8$ ) prior to sequencing. RNA-Seq libraries were sequenced on an Illumina HiSeq 2000 (single-end 100bp). Raw sequence files were obtained using Illumina's proprietary software and are available at NCBI's Gene Expression Omnibus resource (GEO Series accession number GSE67113; http://www.ncbi.nlm.nih .gov/geo/query/acc.cgi?acc=GSE67113) resource. RNA-Seq reads were aligned using STAR v2.3.0 [41]. The GRCm38 assembly (mm10) of the mouse genome and the junction database from Ensembl's gene annotation (release 71) were used as reference for STAR. The count matrix for genes in Ensembl's genome annotation (excluding rRNAs, Mt_rRNAs and Mt_tRNAs) was generated with HTSeqcount v0.5.4p3 (http://www-huber.embl.de/users/anders/ HTSeq/) and normalized using the geometric mean across samples [42]. DESeq v1.14.0 [42] was used to classify genes as differentially expressed (Benjamini-Hochberg adjusted $p$-value $<0.05$ ). Moderate fold changes between conditions were obtained from variance-stabilized data [42]. Functional annotation of differentially expressed genes was generated through the use of DAVID [36, 37]. Hierarchical gene clustering was performed with GENE-E (http://www. broadinstitute.org/cancer/software/GENE-E/). To display the heatmap, the expression levels were re-scaled so that, for each gene, the limits of the color scale correspond to the minimum and maximum expression levels across all samples.

\section{EGR1 transcription factor binding site analysis}

Publically available ENCODE data for EGR1 Transcription Factor Binding Site ChIP-Seq Uniform Peak analysis was downloaded from the UCSC Genome Browser for the K562, H1-hESC, and GM12878 cell lines [27]. For each line, the locations for all EGR1 Transcription Factor Binding Sites (TFBS) were grouped based on the closest known gene based using the UCSC Main (hg19) ccds gene list. The genes with one or more TFBS were compared to the mouse (mm10) RNASeq data set to identify genes that were differentially expressed in the miR-146a-deficient tumors and also had at least one EGR1 TFBS in close proximity to the gene (defined as $3 \mathrm{~kb}$ ). A Chi-Square test was performed with one degree of freedom to compare the relative frequency of EGR1 TFBS in the differentially expressed dataset (Observed) with the frequency across the genome (Expected). Only the mouse genes with a human homolog (total of 16288 genes) were used.

\section{RT-qPCR}

RNA collected from the murine tumors was reverse transcribed using qScript reagent and PerfeCTa SYBR Green FastMix reagent (Quanta Biosciences) or TaqMan MicroRNA Assay (Life Technologies). Primer sequences used are listed in Supplementary Table 1. 


\section{Western blot}

Tumor cell suspensions were lysed in RIPA buffer (Boston BioProducts) supplemented with Halt Protease and Phosphatase Inhibitor Cocktail (Thermo Scientific). Equal amounts of protein lysate (as quantified by using bicinchoninic acid protein assay, BCA (Thermo Scientific)) were electrophoresed on a $5-12 \%$ SDSPAGE and electroblotted onto a nitrocellulose membrane. Antibodies used were c-MYC Rabbit polyclonal (\#9402), EGR1 (44D5) Rabbit monoclonal (all antibodies from Cell Signaling), and B-Actin (AC15) mouse monoclonal antibody (Sigma Aldrich). Secondary HRPconjugated antibodies were purchased from Santa Cruz Biotechnology.

\section{MTS assay}

Cell proliferation was measured using the Promega Cell Titer 96 Aqueous Non-Radioactive Cell Proliferation Assay kit. After addition of reagent according to the manufacturer's protocol, cells were incubated at $37^{\circ}, 5 \%$ $\mathrm{CO}_{2}$ for 4 hours and absorbance was measured at $490 \mathrm{~nm}$.

\section{Luciferase assays}

A 996-bp segment of the human EGR1 3'UTR containing the miR-146a site was cloned into the pmiRGlo dual luciferase vector (Promega). A similar cloning strategy was used to clone murine Egr1 3'UTR and the Nrp2 UTR (see Supplementary Table 1). For mutation of the miR146a binding site, we utilized site-directed mutagenesis as previously described using the primers shown in Supplementary Table 1 [43]. Co-transfections were performed with Lipofectamine 2000 (Life Technologies) as per the manufacturer's instructions. Cells were lysed after 24 hours, substrate was added and luminescence was measured on a Glomax-Multi Jr (Promega).

\section{Genotyping for miR-146a mice and c-Myc mice}

Mice were genotyped for miR-146a deletion and $E \mu-M y c$ presence using DNA extracted from tail samples. Genotyping for miR-146a deletion was done as described previously [11]. Primers are listed in Supplementary Table 1.

\section{ACKNOWLEDGMENTS}

We thank members of the Rao lab for helpful discussions regarding the research. This work was supported by an R01CA166450-01 and Career Development Award K08CA133521 from the National Institutes of Health (DSR). DSR was a Sidney Kimmel Scholar supported by the Sidney Kimmel Foundation for Cancer Research (Translational Award SKF-11-013). JRC was supported by the Eugene V. Cota-Robles Grant and by a training award from the institutional Tumor Immunology training Grant
(NIH T32CA009120). TRF was supported by Tumor Biology Training Grant NIH T32CA009056 from the National Institute of Health. NIRM was supported by the Eugene V. Cota-Robles Fellowship from UCLA and the Graduate Research Fellowship Program from the National Science Foundation. Flow cytometry was performed in the UCLA Jonsson Comprehensive Cancer Center (JCCC) and Center for AIDS Research Flow Cytometry Core Facility that is supported by National Institutes of Health awards AI-28697, and award number P30CA016042, the JCCC, the UCLA AIDS Institute, and the David Geffen School of Medicine at UCLA. We would like to acknowledge the ENCODE project and in particular the EGR1 Transcription Factor Binding Site Chip-Seq data, generated and analyzed by the Hudson Alpha Institute in Huntsville, AL.

\section{CONFLICTS OF INTEREST}

The authors declare no conflicts of interest.

\section{REFERENCES}

1. O'Connell RM, Rao DS, Chaudhuri AA, Baltimore D. Physiological and pathological roles for microRNAs in the immune system. Nature reviews Immunology. 2010; 10:111-122.

2. Bartel DP, Chen CZ. Micromanagers of gene expression: the potentially widespread influence of metazoan microRNAs. Nature reviews Genetics. 2004; 5:396-400.

3. Bartel DP. MicroRNAs: target recognition and regulatory functions. Cell. 2009; 136:215-233.

4. Griffiths-Jones S, Grocock RJ, van Dongen S, Bateman A, Enright AJ. miRBase: microRNA sequences, targets and gene nomenclature. Nucleic Acids Res. 2006; 34:D140-144.

5. Calin GA, Dumitru CD, Shimizu M, Bichi R, Zupo S, Noch E, Aldler H, Rattan S, Keating M, Rai K, Rassenti L, Kipps T, Negrini M, Bullrich F, Croce CM. Frequent deletions and down-regulation of micro- RNA genes miR15 and miR16 at 13q14 in chronic lymphocytic leukemia. Proc Natl Acad Sci U S A. 2002; 99:15524-15529.

6. Klein U, Lia M, Crespo M, Siegel R, Shen Q, Mo T, Ambesi-Impiombato A, Califano A, Migliazza A, Bhagat G, Dalla-Favera R. The DLEU2/miR-15a/16-1 cluster controls $\mathrm{B}$ cell proliferation and its deletion leads to chronic lymphocytic leukemia. Cancer Cell. 2010; 17:28-40.

7. O'Connell RM, Rao DS, Chaudhuri AA, Boldin MP, Taganov KD, Nicoll J, Paquette RL, Baltimore D. Sustained expression of microRNA-155 in hematopoietic stem cells causes a myeloproliferative disorder. The Journal of experimental medicine. 2008; 205:585-594.

8. O'Connell RM, Chaudhuri AA, Rao DS, Baltimore D. Inositol phosphatase SHIP1 is a primary target of miR-155. Proc Natl Acad Sci U S A. 2009; 106:7113-7118. 
9. Boldin MP, Taganov KD, Rao DS, Yang L, Zhao JL, Kalwani M, Garcia-Flores Y, Luong M, Devrekanli A, $\mathrm{Xu}$ J, Sun G, Tay J, Linsley PS, Baltimore D. miR-146a is a significant brake on autoimmunity, myeloproliferation, and cancer in mice. J Exp Med. 2011.

10. Taganov KD, Boldin MP, Chang KJ, Baltimore D. NF-kappaB-dependent induction of microRNA miR146, an inhibitor targeted to signaling proteins of innate immune responses. Proc Natl Acad Sci U S A. 2006; 103:12481-12486.

11. Zhao JL, Rao DS, Boldin MP, Taganov KD, O'Connell RM, Baltimore D. NF-kappaB dysregulation in microRNA-146a-deficient mice drives the development of myeloid malignancies. Proc Natl Acad Sci U S A. 2011; 108:9184-9189.

12. Starczynowski DT, Kuchenbauer F, Argiropoulos B, Sung S, Morin R, Muranyi A, Hirst M, Hogge D, Marra M, Wells RA, Buckstein R, Lam W, Humphries RK, Karsan A. Identification of miR-145 and miR-146a as mediators of the 5q- syndrome phenotype. Nat Med. 2010; 16:49-58.

13. Starczynowski DT, Kuchenbauer F, Wegrzyn J, Rouhi A, Petriv O, Hansen CL, Humphries RK, Karsan A. MicroRNA-146a disrupts hematopoietic differentiation and survival. Exp Hematol. 2010.

14. Yang L, Boldin MP, Yu Y, Liu CS, Ea CK, Ramakrishnan P, Taganov KD, Zhao JL, Baltimore D. miR$146 \mathrm{a}$ controls the resolution of $\mathrm{T}$ cell responses in mice. The Journal of experimental medicine. 2012; 209:1655-1670.

15. Lu LF, Boldin MP, Chaudhry A, Lin LL, Taganov KD, Hanada T, Yoshimura A, Baltimore D, Rudensky AY. Function of miR-146a in controlling Treg cell-mediated regulation of Th1 responses. Cell. 2010; 142:914-929.

16. Zhao JL, Rao DS, O'Connell RM, Garcia-Flores Y, Baltimore D. MicroRNA-146a acts as a guardian of the quality and longevity of hematopoietic stem cells in mice. eLife. 2013; 2:e0537.

17. Alizadeh AA, Eisen MB, Davis RE, Ma C, Lossos IS, Rosenwald A, Boldrick JC, Sabet H, Tran T, Yu X, Powell JI, Yang L, Marti GE, Moore T, Hudson J, Jr., $\mathrm{Lu}$ L, et al. Distinct types of diffuse large B-cell lymphoma identified by gene expression profiling. Nature. 2000; 403:503-511.

18. Ngo VN, Young RM, Schmitz R, Jhavar S, Xiao W, Lim KH, Kohlhammer H, Xu W, Yang Y, Zhao H, Shaffer AL, Romesser P, Wright G, Powell J, Rosenwald A, Muller-Hermelink HK, et al. Oncogenically active MYD88 mutations in human lymphoma. Nature. 2011; 470:115-119.

19. Compagno M, Lim WK, Grunn A, Nandula SV, Brahmachary M, Shen Q, Bertoni F, Ponzoni M, Scandurra M, Califano A, Bhagat G, Chadburn A, DallaFavera R, Pasqualucci L. Mutations of multiple genes cause deregulation of NF-kappaB in diffuse large B-cell lymphoma. Nature. 2009; 459:717-721.

20. Forloni M, Dogra SK, Dong Y, Conte D, Jr., Ou J, Zhu LJ, Deng A, Mahalingam M, Green MR, Wajapeyee N.
miR-146a promotes the initiation and progression of melanoma by activating Notch signaling. eLife. 2014; 3:e01460.

21. Robertus JL, Kluiver J, Weggemans C, Harms G, Reijmers RM, Swart Y, Kok K, Rosati S, Schuuring E, van Imhoff G, Pals ST, Kluin P, van den Berg A. MiRNA profiling in B non-Hodgkin lymphoma: a MYC-related miRNA profile characterizes Burkitt lymphoma. Br J Haematol. 2010; 149:896-899.

22. Chang TC, Yu D, Lee YS, Wentzel EA, Arking DE, West KM, Dang CV, Thomas-Tikhonenko A, Mendell JT. Widespread microRNA repression by Myc contributes to tumorigenesis. Nat Genet. 2008; 40:43-50.

23. Chang TC, Zeitels LR, Hwang HW, Chivukula RR, Wentzel EA, Dews M, Jung J, Gao P, Dang CV, Beer MA, Thomas-Tikhonenko A, Mendell JT. Lin-28B transactivation is necessary for Myc-mediated let-7 repression and proliferation. Proc Natl Acad Sci U S A. 2009; 106:3384-3389.

24. Johansson FK, Goransson H, Westermark B. Expression analysis of genes involved in brain tumor progression driven by retroviral insertional mutagenesis in mice. Oncogene. 2005; 24:3896-3905.

25. Kharbanda S, Nakamura T, Stone R, Hass R, Bernstein S, Datta R, Sukhatme VP, Kufe D. Expression of the early growth response 1 and 2 zinc finger genes during induction of monocytic differentiation. J Clin Invest. 1991; 88:571-577.

26. Dinkel A, Warnatz K, Ledermann B, Rolink A, Zipfel PF, Burki K, Eibel H. The transcription factor early growth response 1 (Egr-1) advances differentiation of pre-B and immature B cells. The Journal of experimental medicine. 1998; 188:2215-2224.

27. Bernstein BE, Birney E, Dunham I, Green ED, Gunter C, Snyder M. An integrated encyclopedia of DNA elements in the human genome. Nature. 2012; 489:57-74.

28. Hu R, Kagele DA, Huffaker TB, Runtsch MC, Alexander M, Liu J, Bake E, Su W, Williams MA, Rao DS, Moller T, Garden GA, Round JL, O'Connell RM. miR-155 promotes $\mathrm{T}$ follicular helper cell accumulation during chronic, lowgrade inflammation. Immunity. 2014; 41:605-619.

29. Frenzel A, Labi V, Chmelewskij W, Ploner C, Geley S, Fiegl H, Tzankov A, Villunger A. Suppression of B-cell lymphomagenesis by the $\mathrm{BH} 3$-only proteins $\mathrm{Bmf}$ and $\mathrm{Bad}$. Blood. 2010; 115:995-1005.

30. Nemajerova A, Petrenko O, Trumper L, Palacios G, Moll UM. Loss of p73 promotes dissemination of Mycinduced B cell lymphomas in mice. J Clin Invest. 2010; 120:2070-2080.

31. Kuehl WM, Brents LA, Chesi M, Huppi K, Bergsagel PL. Dysregulation of c-myc in multiple myeloma. Current topics in microbiology and immunology. 1997; 224:277-282.

32. Dalla-Favera R, Bregni $M$, Erikson J, Patterson D, Gallo RC, Croce CM. Human c-myc onc gene is located on the region of chromosome 8 that is translocated in Burkitt lymphoma cells. Proc Natl Acad Sci U S A. 1982; 79:7824-7827. 
33. Adams JM, Gerondakis S, Webb E, Corcoran LM, Cory S. Cellular myc oncogene is altered by chromosome translocation to an immunoglobulin locus in murine plasmacytomas and is rearranged similarly in human Burkitt lymphomas. Proc Natl Acad Sci U S A. 1983; 80:1982-1986.

34. Battey J, Moulding C, Taub R, Murphy W, Stewart T, Potter H, Lenoir G, Leder P. The human c-myc oncogene: structural consequences of translocation into the $\operatorname{IgH}$ locus in Burkitt lymphoma. Cell. 1983; 34:779-787.

35. Rabbitts TH, Hamlyn PH, Baer R. Altered nucleotide sequences of a translocated c-myc gene in Burkitt lymphoma. Nature. 1983; 306:760-765.

36. Huang da W, Sherman BT, Zheng X, Yang J, Imamichi T, Stephens R, Lempicki RA. Extracting biological meaning from large gene lists with DAVID. Curr Protoc Bioinformatics. 2009; . Chapter 13:Unit 1311.

37. Huang da W, Sherman BT, Lempicki RA. Systematic and integrative analysis of large gene lists using DAVID bioinformatics resources. Nat Protoc. 2009; 4:44-57.

38. Salehi F, Kovacs K, Scheithauer BW, Lloyd RV, Cusimano M. Pituitary tumor-transforming gene in endocrine and other neoplasms: a review and update. Endocr Relat Cancer. 2008; 15:721-743.

39. Appelbe OK, Bollman B, Attarwala A, Triebes LA, MunizTalavera H, Curry DJ, Schmidt JV. Disruption of the mouse Jhy gene causes abnormal ciliary microtubule patterning and juvenile hydrocephalus. Dev Biol. 2013; 382:172-185.

40. Adams JM, Harris AW, Pinkert CA, Corcoran LM, Alexander WS, Cory S, Palmiter RD, Brinster RL. The c-myc oncogene driven by immunoglobulin enhancers induces lymphoid malignancy in transgenic mice. Nature. $1985 ; 318: 533-538$.

41. Dobin A, Davis CA, Schlesinger F, Drenkow J, Zaleski C, Jha S, Batut P, Chaisson M, Gingeras TR. STAR: ultrafast universal RNA-seq aligner. Bioinformatics. 2013; 29:15-21.

42. Anders S, Huber W. Differential expression analysis for sequence count data. Genome Biol. 2010; 11:R106.

43. Rao DS, O'Connell RM, Chaudhuri AA, Garcia-Flores Y, Geiger TL, Baltimore D. MicroRNA-34a perturbs B lymphocyte development by repressing the forkhead box transcription factor Foxp1. Immunity. 2010; 33:48-59. 